\title{
Preparation, Characterization and Properties of a Novel Electrospun polyamide-6/Chitosan/Graphene oxide Composite Nanofiber
}

\section{Atefeh Mousavi}

University of Mazandaran Faculty of Chemistry

Seyed Reza Nabavi ( $\square$ smabavi@umz.ac.ir)

University of Mazandaran Faculty of Chemistry https://orcid.org/0000-0002-2605-6710

\section{Research Article}

Keywords: Electrospinning, Chitosan, Polyamide-6, Graphene oxide, nanofibers, Adsorption

Posted Date: January 24th, 2022

DOI: https://doi.org/10.21203/rs.3.rs-1239500/v1

License: (c) (i) This work is licensed under a Creative Commons Attribution 4.0 International License.

Read Full License 


\section{Abstract}

Chitosan (CS) is a natural biopolymer that due to its excellent properties such as biocompatibility and biodegradability is suitable for use in many applications. But, dependent on the molecular weight and other properties the electrospinning capability of CS is very weak. So, to solve this problem, it is recommended to blend it with a second polymer. In this work, CS/polyamide-6 (PA6) composite nanofibers were fabricated by electrospinning technique. Then different weight percentages of graphene oxide (GO) i.e. $0.1,0.25$, and $0.5 \mathrm{wt}$ \% were used to improve the mechanical and thermal properties of composite nanofibers. The characterization results showed that uniform nanofibers were formed by electrospinning of the PA6/CS nanocomposites blend, and the addition of GO lead to the formation of spider-web-like morphology with decreasing of nanofibers diameter. Further, the GO can improve Young's module and thermal degradability of the PA6/CS nanofibers mat. Finally, the potential of prepared composite nanofibers was investigated for the adsorption of lead ions $\left(\mathrm{Pb}^{2+}\right)$ in a batch system. Kinetic studies and adsorption isotherms revealed that the $\mathrm{Pb}^{2+}$ ion adsorption using $\mathrm{PA6} / \mathrm{CS} / \mathrm{GO}$ adsorbent was pseudo-first-order, and the maximum adsorption capacity was calculated $217.39 \mathrm{mg} \cdot \mathrm{g}^{-1}$.

\section{Introduction}

Polymer nanofibers have a lot of interesting features include flexibility in surface functional groups, excellent mechanical strength, and a high surface area to volume ratio (Xue, Wu et al. 2019). Therefore, they are used in many applications including drug delivery and enzymes immobilization (Ghorbani and Zamanian 2018), tissue engineering (Navaneethan, Vijayakumar et al. 2021), energy storage such as solar cells (López-Covarrubias, Soto-Muñoz et al. 2019), water and wastewater treatment (Yin, Zhang et al. 2020) such as separation (Shakiba, Nabavi et al. 2021), filtration (Jalalian and Nabavi 2020), and adsorption (Sirviö and Visanko 2020, Bandehali, Sanaeepur et al. 2021). Different methods are used to fabricate nanofibers such as interfacial polymerization, drawing, template synthesis, phase separation, electrospinning (Islam, Ang et al. 2019, Leidy, Ximena et al. 2019), and etc.

Electrospinning is the most common technique to produce nanofibers on a large-scale. It is a simple and inexpensive method to produce highly porous and nano-sized fibers with a high surface area to volume ratio. Generally, the electrospinning setup contains three main parts: a high-voltage power supply to charge the polymer solution, a needle with pumps from which the polymer solution is fed, and a collector where nanofibers are accumulated (Thenmozhi, Dharmaraj et al. 2017). Various parameters influence the spinning of the polymer solution, including solution parameters (natural and synthetic polymer, surface tension, viscosity, and conductivity), instrumental parameters (flow rate, applied voltage, distance between tip and collector), and ambient parameters (humidity, temperature, atmosphere) (Islam, Ang et al. 2019). Therefore, the properties of nanofibers can be improved by adjusting operational conditions and solution properties.

Chitosan (CS) is one of the natural polyaminosacharids that obtain by chemical or enzymatic deacetylation of chitin from arthropod shells such as shrimp and crabs (Kardas, Struszczyk et al. 2012). 
Due to the biocompatibility and biodegradability of this biopolymer, CS nanofibers are used in biological (Zhao, Zhou et al. 2018), biomedical (Smirnova, Kolbe et al. 2019), and agricultural applications (YildirimAksoy and Beck 2017). In addition, it has a high potential for water purification by removing and adsorbing contaminants due to the presence of some functional groups such as $\mathrm{OH}$ and $\mathrm{NH}_{2}$ (Zhang, Zeng et al. 2016). However, high molecular weight (HMW) CS has low solubility in most solvents, which limits the electrospinning ability (Zhang, Su et al. 2008). Generally, low molecular weight CS tends to form beads rather than fibers. In contrast, HMW CS gives fibers with a larger average diameter (Sencadas, Correia et al. 2012). Geng et al. have evaluated different molecular weight CS nanofibers fabricated by electrospinning technique. They reported that only medium molecular weight CS can produce continuous and uniform nanofibers (Geng, Kwon et al. 2005).

The main problem in the electrospinning of HMW CS may be due to the higher charge density of the CS molecules contains higher amino groups per molecule (Homayoni, Ravandi et al. 2009). Therefore, synthetic polymers such as polyethylene oxide (Ardeshirzadeh, Anaraki et al. 2015), polyvinyl alcohol (Tamayo Marín, Londoño et al. 2019), and PA6 (Keirouz, Radacsi et al. 2020) are blended with HMV CS to produce uniform nanofibers. The ability to create hydrogen bonds between hydrophilic polymers and CS is one of the important reasons for choosing these polymers to obtain modified composite nanofibers (He, Zhu et al. 2004, Zhang, Liu et al. 2017). Pervez et al, successfully fabricated water-soluble CS (HMV)/polyvinyl alcohol composite nanofiber by electrospinning technique (Pervez and Stylios 2018). Also, Nirwan et al. prepared a continuous morphology of hybrid CS/polyethylene oxide nanofibers containing CS of a relatively HMV (200 kDa) (Nirwan, Al-Kattan et al. 2019).

PA6 is one of the most common polymers that used in fibers, films, and as injectable models in engineering plastics (Illing, Schoßig et al. 2015). The blending of PA6 with other polymers leads to improve the physical and mechanical properties due to the presence of amine and carboxyl groups (Paz, Leite et al. 2016). Many research has been conducted on fabrication of the PA6/ CS nanofiber composites (Maryšková, Ardao et al. 2016, Li, Sellaoui et al. 2019). But the major disadvantages of synthesis/natural composite nanofiber are their decreased thermal and mechanical properties when blended (Koosha and Mirzadeh 2015). To overcome these limitations, various reinforcing nanofillers such as graphene oxide and carbon nanotubes are used in composite nanofiber scaffolds (Liu, Li et al. 2012, Doagou-Rad, Islam et al. 2018, Banitaba, Semnani et al. 2020).

GO has a high surface area and oxygen-functional groups including hydroxyl, carboxyl, and epoxy groups at its sheet corners (Young, Kinloch et al. 2012, Sherlala, Raman et al. 2018). Also it is noteworthy to mention that the incorporation of GO nanoparticles into electrospun nanofibers increases the hydrophilicity of nanofibers owing the significant increase in functional groups, and thus leads to an increase in the adsorption performance of nanofibers (Che Othman, Yusof et al. 2020, Moradi and Zinadini 2020). Therefore, the content of GO in the nanofiber composite matrix could be a considerable element that determines the properties of nanofibers (Liu, Park et al. 2014, Yang, Liu et al. 2018). 
Recently, Feng et al. (Feng, Yuan et al. 2020) reported the preparation of porous polyacrylonitrile/ GO nanofibers by a simple one-step electrospinning process for efficient adsorption of $\mathrm{Cr}^{6+}$ ions from aqueous solutions. Najafabadi et al. (Najafabadi, Irani et al. 2015) examined the adsorption behaviors of $\mathrm{Cu}^{2+}, \mathrm{Pb}^{2+}$ and $\mathrm{Cr}^{6+}$ metal ions from aqueous solutions using chitosan/GO composite nanofibers. In another study, Nylon-6, 6/ GO nanofibers fabricated through the electrospun method and the adsorption behavior of $\mathrm{Cr}^{6+}$ onto Nylon6, 6/GO nanofibers was investigated (Parlayıcl, Avcl et al. 2019). These studies have explored the use of GO nanofiller plays an important role in adsorption capacity of nanocomposite adsorbent in the wastewater treatment process.

In this study, PA6/CS composite nanofiber was fabricated by electrospinning technique, with the aim to investigate the effect of CS content on morphological properties of nanofibrous structures. Also, the effects of adding $\mathrm{GO}$ on the mechanical properties and thermal stability of resulted polymer matrix was studied. Moreover, the ability of composite nanofibers was investigated in the batch adsorption process of heavy metal ions $\left(\mathrm{Pb}^{2+}\right)$.

\section{Experimental}

\subsection{Materials and Methods}

Hydrogen peroxide (35\%), sulfuric acid (98\%), hydrochloric acid (37\%), acetic acid (99\%), potassium permanganate (99\%), graphite powder, and potassium nitrate (99\%) were purchased from Merck. Formic acid and lead nitrate were provided from Fluka. CS powder (HMW: 310000-375000 Da,>75\% deacetylated) was purchased from Sigma-Aldrich. PA6 was obtained from Tehran Aliaf Company. All chemicals were of analytical-reagent grade and were used without further purification.

\subsection{Synthesis of $\mathbf{G O}$}

At first, graphite is converted to graphite oxide using the modified Hummer method (Hummers Jr and Offeman 1958, Ghasemi, Hosseini et al. 2017). Then the amount of $700 \mathrm{mg}$ was added to $115 \mathrm{~mL}$ of concentrated sulfuric acid gradually. This solution stirred intensely in the ice bath. Then, the specific amount of potassium permanganate was added slowly over a period of 45 to 60 minutes. The ice bath was removed, and then $230 \mathrm{~mL}$ of water was added to it gradually after a half hour. Afterwards, $50 \mathrm{~mL}$ of hydrogen peroxide was added into the solution to obtain a yellow solution. In order to neutralization, the solution was filtered and washed with water and acid. The precipitate which is known as graphite oxide was dried in the oven at $50^{\circ} \mathrm{C}$. To preparation of $\mathrm{GO}$ nanosheets, the prepared graphite oxide was added to distilled water, and this combination was placed in an ultrasound bath for 60 minutes to sheets separate from each other completely.

\subsection{Preparation of electrospinning solutions}

CS powder was dissolved in the concentrated acetic acid gradually over several steps to provide $7 \mathrm{wt} \%$ $\mathrm{CS}$, and then stirred for 24 hours at room temperature. To preparation of composite solutions, the specific 
amount of PA6 pellets were dissolved in the formic acid and then CS solution was added to the prepared PA6 solution to obtain different ratios of $2,4,8,12,16$, and $20 \mathrm{wt} \%$ of CS to PA6. Thereafter, the resulting solution was stirred for $1 \mathrm{~h}$ at room temperature. Next step, certain amounts of ultrasonicated GO were added to the optimized PA6/CS solution to be formed $0.1,0.25$, and $0.5 \mathrm{wt} \%$ of GO compounds. Finally, mixture solutions containing $\mathrm{GO}$ and PA6/CS were sonicated for 10 minutes to obtain homogenous solutions for electrospinning.

\subsection{Electrospinning process}

In order to fabrication of electrospun nanofibers, all samples were loaded into a plastic syringe (steel needle, G20). The injecting rate of solutions was $0.6 \mathrm{ml} / \mathrm{h}$, and the voltage was adjusted at $25 \mathrm{kV}$. The distance between the syringe needle and the collector was $16 \mathrm{~cm}$ under room temperature. Then the device started electrospinning by applied condition. The electrospun materials were ejected toward a rotating collector covered with aluminum foil.

\subsection{Characterization of nanofibers}

Thermogravimetric Analysis (TGA STA504 BAHR, Germany), was performed at a temperature range of 25$600{ }^{\circ} \mathrm{C}$ and rate of $10^{\circ} \mathrm{C} / \mathrm{min}$. The functional groups corresponding to the samples were analyzed by Fourier Transform Infrared (FTIR) Spectrum (Bruker spectrometer model 22 Vector, Germany). The Scanning Electron Microscope (SEM, KYKY EM 3200, China) was used for the characterization and investigation of morphological analyses of prepared nanofibers. The average diameter and diameter distribution of nanofibers were obtained with an image analyzer (Digimizer image processing). The mechanical properties were evaluated using tensile test (SANTAM, Iran), and the point of zero charge $\left(\mathrm{pH}_{\mathrm{PZC}}\right)$ was determined using the solid addition method (Cho, Lee et al. 2012).

\subsection{Adsorption study}

The metal adsorption capacity of composite nanofibers was determined in batch experiments. $\mathrm{Pb}^{2+}$ ion solutions were prepared by dissolving lead nitrate in distilled water at room temperature. Adsorption experiments were performed by changing the adsorbent dosage $(0.01-0.1 \mathrm{~g})$, solution $\mathrm{pH}(2-7)$, and constant initial $\mathrm{Pb}^{2+}$ concentration $50 \mathrm{mg} \cdot \mathrm{L}^{-1}$, to determine the optimal adsorption conditions for $\mathrm{Pb}^{2+}$ adsorption. The composite nanofibers were immersed in ion solutions and all samples were continuously shacked on a shaker for $60 \mathrm{~min}$. Also, the adsorption isotherm and the kinetic studies were established using the various initial concentrations of $\mathrm{Pb}^{2+}\left(25-150 \mathrm{mg} \cdot \mathrm{L}^{-1}\right)$ and different contact times (5-120 min). The metal ion concentrations were measured using atomic absorption spectrophotometer (novAA-400 Analytic Jena, Germany).The percentage sorption and the sorption capacity $\left(\mathrm{q}_{\mathrm{e}}\right)$ of $\mathrm{Pb}^{2+}$ were calculated using the following equations

$$
\% \text { Sorption }=\frac{\left(C_{0}-C_{e}\right)}{C_{0}} \times 100
$$




$$
q_{e}=\frac{C_{0}-C_{e}}{m} \times V
$$

where $\mathrm{C}_{0}$ is the initial metal ion concentration $\left(\mathrm{mg}^{-\mathrm{L}^{-1}}\right)$, and $\mathrm{Ce}$ is the equilibrium metal ion concentration $\left(\mathrm{mg} \cdot \mathrm{L}^{-1}\right)$. $\mathrm{V}$ is the liquid volume $(\mathrm{L})$ and $\mathrm{m}$ is the weight of adsorbent nanofibers $(\mathrm{mg})$.

Figure 1.

\section{Results And Discussion}

\subsection{Characterization of electrospun nanofibers 3.1.1. FTIR results}

FTIR analysis was used to investigate the interaction between constituents. Figure 2 illustrates the various FTIR spectra of nanofibers; a) pure PA6, b) pure CS, c) composite nanofibers of PA6/CS, d) GO, and e) composite nanofibers of PA6/CS/GO which was investigated in the range of $400-4000 \mathrm{~cm}^{-1}$. In the spectra of PA6 nanofibers, two branches broad peaks appear to represent the second type of $-\mathrm{NH}$ functional group in the range of $3200-3500 \mathrm{~cm}^{-1}$. Also, the indicator peak in the $2945 \mathrm{~cm}^{-1}$ demonstrates the $\mathrm{C}-\mathrm{H}$ methylene bond in its structure. Other peaks appear in 1571 and $1639 \mathrm{~cm}^{-1}$ which are related to $\mathrm{C}=\mathrm{O}$ stretching and $\mathrm{N}-\mathrm{H}$ vibration bonds in the PA6 structure (Tsou, Lin et al. 2013). In the spectrum of CS, the broad peak in $1418 \mathrm{~cm}^{-1}$ wavenumber belongs to $-\mathrm{NH}$ and $-\mathrm{OH}$ stretching bonds which this expansion continues from $3200-3600 \mathrm{~cm}^{-1}$. The appeared peak in $2918 \mathrm{~cm}^{-1}$ is referred to stretching $\mathrm{CH}_{2}$ group. Moreover, the peaks with 1570 and $1659 \mathrm{~cm}^{-1}$ wavenumber are assigned to the first and second types of the amino groups binding of CS structure (Liu, Park et al. 2014). Furthermore, the FTIR spectrum of PA6/CS nanocomposites exhibits the characteristic bonds at 1549 and $1645 \mathrm{~cm}^{-1}$. These peaks show the shift of index peaks of $\mathrm{C}=\mathrm{O}$ stretching and $\mathrm{N}-\mathrm{H}$ vibration bonds in the PA6 and amine peaks of $\mathrm{CS}$. This displacement indicates the hydrogen bond created by the interaction of hydroxyl and amine hydrogens in the structure of both polymers (Kummer, Schonhart et al. 2018). Finally, the FT-IR spectrum of PA6/CS nanocomposites is illustrated by the construction interaction between these two polymers in the formation of weak covalent and intermolecular hydrogen bonds. The FT-IR spectra of synthesized GO implies several functional groups. The broadband in the range of 3000 to $3500 \mathrm{~cm}^{-1}$ is related to the hydroxyl functional group which appears in this spectrum in the wavenumber of $3427 \mathrm{~cm}^{-1}$ that confirms the presence of trapped water molecules in the GO structure. As well as the peak at about $2924 \mathrm{~cm}^{-1}$ is related to the stretch vibration of $-\mathrm{CH}$ with $\mathrm{sp}^{2}$ hybridization. The peaks that appear at $1742 \mathrm{~cm}^{-1}$ is corresponding to the carbonyl functional group. In addition, a sharp peak appears in $1629 \mathrm{~cm}^{-1}$ which belongs to the $\mathrm{C}=\mathrm{C}$ bond of $\mathrm{GO}$ structure that probably overlaps with the $-\mathrm{OH}$ group water and appears more intensely. The peaks of $1007 \mathrm{~cm}^{-1}$ and $1069 \mathrm{~cm}^{-1}$ in the synthetic sample range confirmed the presence of stretching and bending of the $\mathrm{C}-\mathrm{O}$ and $\mathrm{C}-\mathrm{O}-\mathrm{C}$ bonds. An indicator peak with $1171 \mathrm{~cm}^{-1}$ wave 
number indicates the stretch vibration of $\mathrm{C}-\mathrm{O}$ of the alkoxy or epoxy functional groups and the presence of a sharp peak in the $1286 \mathrm{~cm}^{-1}$ region is the mark of the existence of the $\mathrm{C}-\mathrm{OH}$ bond (Jin, Yue et al. 2014) (Silvestri, Mikšíček et al. 2019). The presence of these functional groups at the surface of GO nanosheets adds the hydrophilicity of this material which can be one of the advantages of GO for use as a nanomaterial in addition it is a good reason for its sufficient mechanical properties.

In order to inquire about the effect of the presence of $\mathrm{GO}$ on the structure of composite nanofibers than the polymer matrix, the broad peak in the $3400 \mathrm{~cm}^{-1}$ area shows that the $-\mathrm{OH}$ and $-\mathrm{NH}$ groups are in their structure. This peak appears more intense compared to the peak in their pure state spectrum. This suggests overlapping and strengthening of these functional groups in the combination of nanocomposites which leads to increased peak intensity. In addition, the peaks in 2937, 1643, and 1553 $\mathrm{cm}^{-1}$ demonstrate the methylation of $\mathrm{C}-\mathrm{H}, \mathrm{C}=\mathrm{O}$, and the vibrational $\mathrm{N}-\mathrm{H}$ related to the structure of PA6 in the nanocomposites composition. It is due to the hydrogen bond between these functional groups in PA6 with CS Hexagonal ring and the functional groups of GO which the displacement switching to lowfrequency. Another shift of this type becomes ostensible in $1169 \mathrm{~cm}^{-1}$ is the marker of stretching vibration of C-O of the alkoxy or epoxy functional groups (Liu, Li et al. 2012, Li, Ren et al. 2013, Tavakoli, Karbasi et al. 2020).

\section{Figure 2.}

The formation of hydrogen bonding is a powerful and significant interaction due to the presence of $\mathrm{OH}$ and $\mathrm{NH}$ functional groups in the structure of the composition. It is verifiable according to the recorded FTIR spectrum for PA6/CS/GO composite nanofiber. Therefore, can be expected the change in some of the physical and mechanical properties of nanocomposites.

\subsubsection{SEM analysis results}

The SEM was employed to analyze the surface morphology of composite nanofibers. The SEM images of $7 \mathrm{wt} \%$ CS solution in acetic acid are presented in Figure 3. The morphology and the survey of the prepared nanomaterial are carried out by Digimizer image processing. As well as, the statistical calculations of their histogram are performed by selecting 100 points. As shown in Figure 3, only more regular particles with nonmetric size are obtained, and it is not possible to achieve the nanofibers structure. The molecular weight of the polymer is one of the most important factors in the formation of nanofibers due to its direct effect on viscosity, conductivity, and surface tension. It is concluded that the formation or non-formation of CS nanofibers is dependent on the molecular weight of CS powder. In this study, CS powder with high molecular weight in pure form was investigated. As illustrated in Figure2 and according to Geng et al. report, the formation of nanofibers in this molecular weight is not impossible (Geng, Kwon et al. 2005).

\section{Figure 3.}

According to the SEM images in Figure 4, the formation of nanofibers accrues by electrospinning of the PA6/CS nanocomposites blend in weight percentages of 2 to $20 \mathrm{wt} \%$ of CS in comparison to $16 \%$ PA6, in 
a common solvent of formic acid. Because the purpose of the study was to investigate the effect of CS in the composition the percentage of less than $2 \mathrm{wt} \%$ was neglected. On the other hand, the weight percentages of more than $20 \mathrm{wt} \%$ were investigated experimentally and it was observed that by increasing the amount of $\mathrm{CS}$, the viscosity of the polymer solution prevented its continuous flow in the electrospinning syringe and leads to the difficulty of spinning conditions up to $30 \%$ by weight and nonforming of nanofibers at higher concentrations than that (Zhang, Li et al. 2009). Therefore, this interval was selected in order to study the effect of CS on the polymer matrix.

It can be seen in the SEM images in all the examined percentages, fibers with nano-sized dimensions without beads and fractures were fabricated. Therefore, statistical analysis was used in order to more accurate study. Statistical analysis can be used to determine the fiber size distribution and the evaluation of arithmetic weighted mean of fiber diameter and dispersion (Heikkilä and Harlin 2008). The calculations were carried out with the histogram diagram for each specimen presented in Figure 4 and the diameter of the fibers was measured in $\mathrm{nm}$.

Arithmetic weighted mean $(\lambda w)$ and weighted standard deviation (Sw) are calculated as follow;

$$
\lambda_{w}=\lambda_{0}+\frac{h}{N} \sum_{j=1}^{m} \mathrm{u}_{\mathrm{j}} F C_{j}
$$

$$
S_{W}=\sqrt{\left(\frac{1}{N} \sum_{j=1}^{m}\left(u_{j}^{2} F C_{j}\right)-\left(\frac{1}{N} \sum_{j=1}^{m}\left(u_{j} F C_{j}\right)^{2}\right)\right)} \cdot h^{2}
$$

4

Which in these correlations $\mathrm{m}$ is number of bins and $\mathrm{h}$ is bin width that calculated as follow as equation (5). FC and $\mathrm{N}$ is frequency count and number of statistical samples, respectively. As well as $u$ is the defined variable of equation (6) which in that $\lambda c$ is the bin characteristic or bin center, and $\lambda_{0}$ is the dominant characteristic of the statistical set that corresponds to the highest peak. Finally, $Y$ is the quality loss function which briefly defines as the identifier of the second-order effect of both the weighted arithmetic mean and standard deviation as a response for factorial modeling and optimization has been considered, is defined as the following function;

$$
h=\frac{\lambda_{\max }-\lambda_{\min }}{m}
$$

$$
u=\frac{\left(\lambda c-\lambda_{0}\right)}{h}
$$




$$
Y=\lambda_{W}^{2}+S_{W}^{2}
$$

7

where the low value of $Y$ is favorable. In other words, the lower quantity of $Y$ is due to the smaller diameter mean and the narrower distribution of the fiber diameter (Essalhi, Khayet et al. 2013).

\section{Figure 4}

The obtained results of the statistical calculations for each SEM image are presented in Table (1). According to Table (1), the nanofibers diameter increasing by enhancing the amount of CS to PA6 polymer matrix till $8 \mathrm{wt} \%$ of nanofibers. As well as, in the histogram diagram the growth in the nanofibers diameter of these compounds from $140 \mathrm{~nm}$ in pure PA6 to $461 \mathrm{~nm}$ in a $8 \mathrm{wt} \% \mathrm{CS}$ sample along with an increase in dispersion of the nanofibers diameter distribution gradually is observed. In Figure $4 \mathrm{a}$ and $4 \mathrm{f}$, samples which belong to pure PA6 and PA6/CS 16\% the thinner nanofibers with more integrity along their length and with more regular makeup is obtained. Also, Figure $4 \mathrm{c}$ and $4 \mathrm{~d}$ images are correspond to PA6/CS $4 \%$ and $8 \%$ by weight respectively, which adhesion and shrinkage in the fibers is observed. According to Table (1) and the results obtained in the range of $2-8 \%$ by augmenting amount of CS polymer in the PA6/CS composites, the mean diameter of the nanofibers and the arithmetic weighted mean $(\lambda w)$ and the standard deviation (Sw) has also increased. These effects show larger dispersion of the nanofibers size than the average and inappropriate distribution of their diameter along with increasing in diameter which eventually led to an increasing trend of $Y$ function. The recorded trend may be occurred because of increasing in the viscosity of the PA6 solution due to increase in CS polymer. Also, addition of CS leads to increases the diameter of the nanofibers due to more resistance of solution versus drag by loaded charges on the accelerated flow of solution (Thompson, Chase et al. 2007, Heikkilä and Harlin 2008). 
Table 1

The results of the statistical analysis calculation of the distribution of the diameter of the PA6/CS/GO composite nanofibers

\begin{tabular}{|llllll|}
\hline Sample & $w$ t\% CS & Mean(nm) & $\lambda w(n m)$ & Sw(nm) & $Y\left(\mathrm{~nm}^{2}\right)$ \\
\hline A & 0 & 140 & 142 & 31 & 21,300 \\
\hline B & 2 & 259 & 261 & 49 & 70,900 \\
\hline C & 4 & 416 & 413 & 146 & 192,300 \\
\hline D & 8 & 461 & 462 & 143 & 234,600 \\
E & 12 & 369 & 370 & 99 & 146,800 \\
F & 16 & 297 & 294 & 57 & 90,000 \\
\hline G & 20 & 382 & 380 & 96 & 154,000 \\
H & 24 & 429 & 406 & 98 & 175,000 \\
\hline
\end{tabular}

Reduction of diameter of nanofibers in $12 \%$ and $16 \%$ percentages of weight observed. However, the composition of $16 \mathrm{wt} \%$ in Figure $4 \mathrm{e}$ has the same morphology with the combination of $2 \% \mathrm{CS}$. Decrease in the mean and dispersion of diameters size is visible well in Figure $4 e$ and $3 f$, and $S w$ and $\lambda w$ values for $12 \%$ and $16 \%$ samples in Table (1). The mean diameter for the $12 \%$ and $16 \%$ compounds was obtained $369 \mathrm{~nm}$ and $297 \mathrm{~nm}$ respectively. In justifying these observations, it can be noticed that the conductivity of the polymer solution increases and overcomes the viscosity of the solution by increasing the amount of CS. In this case, with augmenting electrical conductivity the elongation of the solution increases and the fiber with less diameter is produced (Nirmala, Navamathavan et al. 2014).

In Figure $4 \mathrm{~g}$ and $4 \mathrm{~h}$, increasing the diameter of the nanofibers to $429 \mathrm{~nm}$ was occurred and as well as the regular and uniform structure of it was started to change by further enhance in CS concentration up to $24 \%$. While the $\lambda w$ values of them is obtained less than same diameters of them in $4 \%$ and $8 \%$ samples. This result indicates a better distribution and less dispersion of the diameter of the nanofiber. That means the nanofibers diameter was changed seamlessly and the formation of nanofibers was accompanied by overall increase in the diameter of the materials. This phenomenon can be attributed to increase in the density of surface charge of composed jet during electrospinning with increasing CS as an ionic polyelectric. This phenomenon leads to the deformation and degradation of the shape of the nanofibers in the presence of an electric field so that nanofibers cannot be formed at higher percentages (Zhang, Li et al. 2009).

Composite nanofibers were obtained according to the SEM images in the single solvent system based on the histogram and statistical calculations. It is concluded that $2 \%$ and $16 \%$ CS compounds by weight have better conditions of dispersion and nanofibers diameter. Therefore, these two cases are suitable to preparation of PA6/CS/GO composite nanofiber. Because of the goal is the survey of the effect of CS on the composition of the composite, the combination of $16 \%$ was chosen to continue the studies. 
The SEM images are presented in Figure 5 in order to investigate the effect of GO with $0.1 \%, 0.25 \%$ and $0.5 \%$ weight percentages in the structure of the electrospun composite nanofibers. Furthermore, the average diameter of nanofibers measured by histogram calculation presented in Table (2). Results show that the addition of Go lead to decreasing of nanofibers diameter. Also according to the Figure 5 , it can be seen a dual morphology appears in the fiber with the increase of GO into the polymer matrix. So, the structure of Spider-web-like has appeared in the fiber bed. This fibrous structure achieved from the formation of nanofibers with bi-modal diameter. Among the Polymer materials PA6 is the first polymer that has shown this behavior due to the addition of GO and also carbon nanotubes (Wang, Ding et al. 2013, Navarro-Pardo, Martinez-Hernandez et al. 2016). The formation of this form of nanofibers attributed to the fast solvent degradation of polymer caused by well dispersed GO sheets through the electrospinning solution (Wang, Ding et al. 2013). It can be suggested that adding the GO to the polymer matrix augments the electrical conductivity and the instability of the Taylor cone. While the production of electrostatic forces will be larger and jet stretching will be completely possible for the optimal formation of nanoweb due to high voltage applied (Pant, Park et al. 2012). As clear in Figure 5a the concentration of $0.1 \mathrm{wt} \%$ of GO in the polymer matrix causes formation of the spider-web-like structure and also the beads on the surface of the nanofibers were formed. The spider-web-like structure was increased by increasing the amount of GO from $0.1 \mathrm{wt} \%$ to 0.25 and $0.5 \mathrm{wt} \%$.

\section{Figure 5.}

Table 2

Average diameter of PA6/CS/GO electrospun composite nanofibers.

\begin{tabular}{|llllll|}
\hline Sample & $\%$ GO & Average diameter of nanofibers & $\lambda w(n m)$ & $S w(n m)$ & $Y(n m)$ \\
\hline & 0.1 & 267 & 315 & 2.865 & 99,548 \\
\hline PA/CS/GO & 0.25 & 252 & 300 & 2.487 & 90,306 \\
\hline 0.5 & 216 & 655 & 3.409 & 429,036 \\
\hline
\end{tabular}

\subsection{Thermal Analysis results}

TGA analysis was used to investigate the thermal decomposition and thermal properties of formed nanofibers and the impact of GO on them. The TGA graphs of pure PA6 nanofibers, pure CS, PA6/CS and PA6/CS/GO electrospun composite nanofibers are presented in Figure 6-1. The derivative curve of the TGA analysis is also shown in Figure 6-2. As seen as in Figure 6-1, at first all graphs exhibit a same descending pattern between $25^{\circ} \mathrm{C}$ and $130^{\circ} \mathrm{C}$, which is attributed to loss of the adsorbed and bound water of moisture in the samples. The moisture content of the material is lost as the temperature increases, the amount of impurities is reduced, and the material is dried. The graphs $5 \mathrm{a}$ and $5 \mathrm{~b}$ correspond to the samples of PA6 and CS nanofiber. It is clear that the PA6 nanofibers exhibits very good thermal resistance and are completely stable to the temperature range of $190^{\circ} \mathrm{C}$ according to the DTG curve of PA6. After this temperature the decreasing of sample mass is started and the nanofiber displayed a loss of weight about $10 \%$ to the temperature of about $360^{\circ} \mathrm{C}$. The subsequent step at $470{ }^{\circ} \mathrm{C}, 82 \%$ of the total mass is lost and 
this corresponded to decomposition of PA6's Chain. The PA6's major chain degradation situated at 560 ${ }^{\circ} \mathrm{C}$. Whereas CS shows a less thermal stability, and the sample destruction started at the temperature range of $167^{\circ} \mathrm{C}$. As shown in the TGA curve, the large amount of the CS sample mass is completely destroyed to temperature of $370^{\circ} \mathrm{C}$. It is necessary to note that about $30 \%$ of the CS remained after the heating cycle. The DTG graphs of composite nanofibers presented different behavior degradation. The first decomposition of PA6/CS composite nanofiber occurs at range of 187-350 (graph 5-1, 2(c)). Afterward, major mass loss is observed up to $480^{\circ} \mathrm{C}$ and more than $85 \%$ of nanofiber is destroyed. While, the remainder left after decomposition in this sample is about $7 \%$. Also what is obvious is the increase in PA6/CS thermal resistance compared to the CS and the peak temperature for composite nanofibers shifted up, due to the combination of CS with PA6.

Thus, with the addition of $\mathrm{GO}$ to polymer matrix of PA6/CS nanocomposites, the sample degradation is performed at a higher temperature Figure $6 \mathrm{~d}$. In the combination of PA6/CS/GO composite nanofibers the range of first weight reduction is changed to $204-354^{\circ} \mathrm{C}$. Additionally, $80 \%$ of total weight loss at $477^{\circ} \mathrm{C}$, and $8 \%$ of composite nanofibers is remained after the program ended. In justifying of this phenomenon, it seems the penetration of two-dimensional sheets of $\mathrm{sp}^{2} \mathrm{GO}$ in the polymer matrix helping to stronger connection between the PA6 and CS chains, and moreover acts as a barrier against the thermal decomposition and increases the degradation temperature. So that the nanocomposite is destroyed in the higher temperature (Barzegar, Bello et al. 2015). High thermal resistance of composite nanofibers is a good rating for this composition for use in their various applications.

\section{Figure 6.}

\subsection{Mechanical properties}

All polymers, depending on their use must have a certain range of suitable mechanical properties for use. Tensile, compressive, flexural strength and impact resistance are the most important factor for the manufacturer of polymer. Therefore, the mechanical properties of the produced nanocomposite were investigated by tensile properties. Tensile strength refers to fracture resistance. The tensile strength is determined by stretching of a uniformly sized polymer piece. The tensile strength stress is the applied

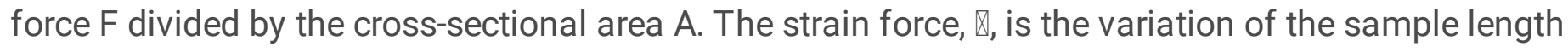
divided by the initial length. $E$ is called Young's modulus, which is the ratio of stress to strain. Since the strain is dimensionless, the Young's modulus is equivalent to the stress $\sigma$ (Amiryaghoubi, Fathi et al. 2021).

Investigation of stress-strain curves is one of the methods of detecting fibers from plastics and elastomers. Elastomers have little initial gradient change and change dramatically after elongation. But both plastics and fibers first show a sharp slope (high variations) until they reach the Yield point or break point. Before this point, stretching is reversible. Sufficient tension is applied at this point, so the deformation then occurs, until the length becomes irreversible. Eventually the sample breaks. Therefore, by drawing the stress-tension diagram, $\mathrm{E}$ is obtained from the slope of the graph. 
The stress-strain curves of the electrospun nanofibers PA6, PA6/CS, and PA6/CS/G0 with different contents of $\mathrm{GO}$ are shown in Figure 7. The measured mechanical properties including Young's modulus, tensile strength and elongation at break were provided in Table (3). As can be seen, electrospun PA6 nanofiber had a high tensile stress of $5.67 \mathrm{MPa}$, with a tensile strain of $29.99 \%$, and the Young's modulus of PA6 were $39 \mathrm{MPa}$. However, the Young's modulus of $9 \mathrm{MPa}$ and tensile strength of $1.04 \mathrm{MPa}$ with an elongation of $11.24 \%$ was observed for PVA/CS composite nanofibers. hence it was expected that the addition of the GO into the polymer matrix might increase resistance mechanical strength (Kennedy and Hudson 1968, Karsli and Aytac 2013) with Young's modulus of PA6/CS/GO were 5.9 MPa and 9.66 MPa for 0.25 and $0.5 \mathrm{wt} \%$ of GO, respectively. The tensile stress and strain of PA6/CS/GO nanofiber at concentration of $0.5 \mathrm{wt} \% \mathrm{GO}$ increased to $1.27 \mathrm{MPa}$ and 10.24 , due to the high resistivity of GO. Consequently, the mechanical strength of composite nanofibers was increased by increasing the amount of $\mathrm{GO}$ to the polymer matrix.

Figure 7

Table 3

The results of tensile test of PA6 electrospun nanofibers, and the electrospun composite nanofibers of PA6/CS $16 \%$, PA6/CS/GO $0.25 \%$, and PA6/CS/GO $0.5 \%$.

\begin{tabular}{|c|c|c|c|c|}
\hline Sample & & $\begin{array}{l}\text { Tensile strength } \\
(\mathrm{MPa})\end{array}$ & $\begin{array}{l}\text { Elongation at } \\
\text { break (\%) }\end{array}$ & $\begin{array}{l}\text { young's modulus (E) } \\
(\mathrm{MPa})\end{array}$ \\
\hline PA6 & - & 5.68 & 29.94 & 37.4 \\
\hline PA6/CS 16\% & - & 1.04 & 11.24 & 5.3 \\
\hline $\mathrm{PA6} / \mathrm{CS} / \mathrm{GO}$ & $0.25 \%$ GO & 1.11 & 10.24 & 5.25 \\
\hline & $0.5 \%$ GO & 1.27 & 9.67 & 9.66 \\
\hline
\end{tabular}

The $\mathrm{pH}$ of the solution is one of the influential factors in the removal process, since the type of surface charges, possessed by the adsorbents and the adsorbent's ionic character affects adsorption ability to remove heavy metals. To identify the optimum $\mathrm{pH}$ for effective adsorption of $\mathrm{Pb}^{2+}$ using PA6/CS/GO composite nanofibers, $\mathrm{Pb}^{2+}$ solutions were prepared at initial concentrations of $50 \mathrm{mg} \cdot \mathrm{L}^{-1}$. Then their $\mathrm{pH}$ was adjusted from 1 to 7 with $0.1 \mathrm{M} \mathrm{HCl}$ and/or $\mathrm{NaOH}$. The adsorbent dosage of $0.5 \mathrm{~g} / \mathrm{L}$, contact time of $60 \mathrm{~min}$, and room temperature were constant conditions.

As shown in Figure 8, it can be seen that the adsorption of $\mathrm{Pb}^{2+}$ increases with increasing $\mathrm{pH}$. But at $\mathrm{pH}=$ 6 a decrease in the adsorption is observed. It can be said that at acidic $\mathrm{pH}(\mathrm{pH} 2,3)$, the carbonyl and amine functional groups present on the adsorbent surface appear as protons $\left(\mathrm{H}^{+}\right)$. Ultimately repulsion between $\mathrm{Pb}^{2+}$ ions and $\mathrm{H}^{+}$centers of adsorbent might have led to the low adsorption capacity of 
composite nanofibers, which has been reported in other studies (Qin, Zhou et al. 2016, Abu-Danso, Peräniemi et al. 2018).

At higher $\mathrm{pH}\left(\mathrm{pH} 4\right.$ and 5), $\mathrm{H}^{+}$ions are available in less amount, so the adsorbent surface became negative and the adsorption capacity increases. On the other hand, at solution $\mathrm{pH}>\mathrm{pHpzc}=4.75$ the surface charge of the adsorbent is negative, so it is suitable for the adsorption of positive ions.

On the other hand, the precipitate was formed in $\mathrm{Pb}^{2+}$ solutions at $\mathrm{pH}$ above 6 . The formation of hydroxylated complexes of $\mathrm{Pb}^{2+}$ in the forms of $\mathrm{Pb}(\mathrm{OH})_{2}, \mathrm{~Pb}_{2}(\mathrm{OH})_{3}{ }^{+}$, and $\mathrm{Pb}_{3}(\mathrm{OH})_{4}{ }^{+}$for lead ions resulted in decreasing adsorption capacities of $\mathrm{Pb}^{2+}$ using composite nanofibers. This phenomenon causes a problem in the adsorption study at higher $\mathrm{pH}$.ally, according to the obtained results, $\mathrm{pH}=5$ was selected as the appropriate $\mathrm{pH}$ for further studies to avoid the formation of $\mathrm{Pb}^{2+}$ precipitates (Razzaz, Ghorban et al. 2016).

\section{Figure 8.}

\subsubsection{Effect of adsorbent dosage}

For investigating the effect of absorbent dosages on the adsorption of $\mathrm{Pb}^{2+}$, the amount of PA6 was changed from 0.01 to $0.1 \mathrm{~g}$ at $50 \mathrm{~mL}$ of lead metal solutions with initial concentrations of $50 \mathrm{ppm}$, and other operational parameters were adjusted at $\mathrm{pH}=5$, contact time $60 \mathrm{~min}$, and at $25^{\circ} \mathrm{C}$. The results of this experiment are presented in Figure 9. It is observed that the adsorption of $\mathrm{Pb}^{2+}$ increased proportionally with PA6/CS/GO dosage, and the highest percentage sorption was recorded by the highest adsorption dosage. The increase in the percentage sorption with increasing PA6/CS/GO is attributed to increased number of adsorption sites on the surface of adsorbent which are available for binding $\mathrm{Pb}^{2+}$ with composite nanofibers (Jawad, Ngoh et al. 2018).

But it is necessary to mention the important factor for the selection of optimum dosage is adsorption capacity. As shown in Figure 9a, the adsorption capacity decreased by increasing the adsorbent dosage according to the relevant equation. Therefore $0.25 \mathrm{~g}$ of PA6/CS/GO was selected for the following experiments.

\section{Figure 9}

\subsubsection{Effect of contact time and adsorption kinetics}

The effect of contact time on the adsorption of $\mathrm{Pb}^{2+}$ ions using PA6/CS/GO composite nanofibers at initial concentrations of $50 \mathrm{ppm}$, the adsorbent dosage of $0.5 \mathrm{~g} \cdot \mathrm{L}^{-1}, \mathrm{pH}=5$, and temperature of $25^{\circ} \mathrm{C}$ is shown in Figure 10. According to the results an increase in the adsorption process is observed up to 20 minutes, and from 20 to 60 minutes, adsorption capacity slightly increased, and the reaction reached equilibrium within $60 \mathrm{~min}$. Due to the small difference in adsorption rate in this interval, 20 minutes is selected as the equilibrium time of the adsorption process. The higher adsorption capacities of $\mathrm{Pb}^{2+}$ ions 
using composite nanofibers could be attributed to the easy diffusion of metal ions into the pores of PA6/CS/GO composite nanofibers.

Kinetic models including pseudo-first-order and pseudo-second- order models were used to describe the adsorption kinetics according to the follows equations.

Pseudo- first- order

$$
q_{t}=q_{e}\left(1-\exp \left(-k_{1} t\right)\right)
$$

8

Pseudo- second- order $q_{t}=\frac{k_{2} q_{e}^{2} t}{1+k_{2} q_{e} t}(9)$

Where $\mathrm{q}_{\mathrm{e}}$ and $\mathrm{q}_{\mathrm{t}}$ represent the adsorption capacities of metal ions $\left(\mathrm{mg} \mathrm{g}^{-1}\right)$ at equilibrium time and time $\mathrm{t}$ ( $\mathrm{min})$, respectively. $\mathrm{k}_{1}\left(\mathrm{~min}^{-1}\right)$ and $\mathrm{k}_{2}\left(\mathrm{~g} \mathrm{mg}^{-1} \mathrm{~min}^{-1}\right)$ are the pseudo-first- order and the pseudo-second order rate constant, respectively (Ghadamnan, Nabavi et al. 2019). The adsorption kinetics of $\mathrm{Pb}^{2+}$ on the PA6/CS/GO composite nanofibers is shown in the Figure 10. The results are summarized in Table (4). According to the experimental adsorption capacities $\left(\mathrm{q}_{\mathrm{e}, \mathrm{exp}}\right)$, the calculated adsorption capacities $\left(\mathrm{q}_{\mathrm{e}, \mathrm{cal}}\right)$, and the related correlation coefficient $\left(R^{2}\right)$ in each of the models, the adsorption kinetics data of metal ions onto the PA6/CS/GO composite nanofibers were best fitted by the pseudo-first- order kinetic model $\left(R^{2}=0.9967\right)$. These results indicate that the absorption velocity controlled by the diffusion process through the mass transfer layer (Zhang, Shi et al. 2019).

Figure 10

Table 4

The adsorption kinetics parameters of $\mathrm{Pb}^{2+}$ ions adsorption using PA6/CS/GO composite nanofibers.

Pseudo- first- order Pseudo- second- order

\begin{tabular}{|lllllll}
$\mathrm{q}_{e, \exp }\left(\mathrm{mg} \mathrm{g}^{-1}\right)$ & $\mathrm{q}_{e, \text { cal }}\left(\mathrm{mg} \mathrm{g}^{-1}\right)$ & $\mathrm{k}_{1}\left(\mathrm{~min}^{-1}\right)$ & $\mathrm{R}^{2}$ & $\mathrm{q}_{e, \text { cal }}\left(\mathrm{mg} \mathrm{g}^{-1}\right)$ & $\mathrm{k}_{2}\left(\mathrm{~g} \mathrm{mg}^{-1} \mathbf{m i n}^{-1}\right)$ & $\mathrm{R}^{2}$ \\
\hline 84.68 & 96.117 & 0.192 & 0.9967 & 113.636 & 0.0014 & 0.988 \\
\hline
\end{tabular}

\subsubsection{Adsorption isotherm studies}

In this study, the equilibrium data of $\mathrm{Pb}^{2+}$ ions sorption onto the PA6/CS/GO composite nanofibers adsorbent were investigated using two models including Langmuir and Friendlich isotherm models. The adsorption isotherms are identified by certain constants that indicate the surface properties and the tendency of the adsorbent. The Langmuir and Freundlich isotherm models assumes the monolayersurface adsorption and heterogeneous-surface adsorption with uniform energies of active sites, 
respectively (Karthik and Meenakshi 2015, Shaker 2015). The isotherm models can be expressed by the following equations:

Langmuir isotherm model: $\frac{C_{e}}{q_{e}}=\frac{1}{q_{\max } k_{L}}+\frac{1}{q_{\max }} C_{e}(10)$

Freundlich isotherm model: $\ln q_{e}=\ln k_{f}+\frac{1}{n} \ln C_{e}(11)$

Where $\mathrm{C}_{\mathrm{e}}, \mathrm{q}_{\mathrm{max}}$, and $\mathrm{q}_{\mathrm{e}}$ are the equilibrium concentration $\left(\mathrm{mg} \cdot \mathrm{L}^{-1}\right)$, the maximum capacity $\left(\mathrm{mg} \cdot \mathrm{g}^{-1}\right)$, and the amount of adsorbed species per specified amount of adsorbent $\left(\mathrm{mg} \cdot \mathrm{g}^{-1}\right)$, respectively. $\mathrm{k}_{\mathrm{L}}\left(\mathrm{L} \cdot \mathrm{mg}^{-1}\right)$ is the Langmuir constants associated to the adsorption affinity. $\mathrm{k}_{\mathrm{f}}\left(\mathrm{mg} \cdot \mathrm{g}^{-1}\right)$ and $1 / \mathrm{n}$ are the Freundlich isotherm constants related to the adsorption capacity and intensity, respectively. The calculated parameters of isotherm models are shown in Table (5). Based on the obtained results, it was found that the Langmuir adsorption isotherm model $\left(R^{2}>0.987\right)$ fitted better than that of Freundlich $\left(R^{2}=0.936\right)$ adsorption isotherm model and the maximum adsorption capacity of PA6/CS/GO nanoadsorbent was calculated $217.39 \mathrm{mg} \cdot \mathrm{g}^{-1}$. This result confirmed the monolayer coating of lead metal on the adsorbent as well as the homogeneous distribution of active sites on the adsorbent.

Table 5

Isotherm parameters of $\mathrm{Pb}^{2+}$ ions adsorption using $\mathrm{PA6} / \mathrm{CS} / \mathrm{GO}$ composite nanofibers.

\begin{tabular}{|llllll|}
\hline \multicolumn{2}{|l|}{ Freundlich isotherm } & \multicolumn{4}{l|}{ Langmuir isotherm } \\
\hline $\mathbf{k}_{\mathbf{f}}\left(\mathbf{m g} \cdot \mathbf{g}^{-1}\right)$ & $\mathbf{n}$ & $\mathbf{R}^{2}$ & $\mathbf{k}_{\mathbf{L}}\left(\mathrm{L} \cdot \mathbf{m g}^{-1}\right)$ & $\mathbf{q}_{\max }\left(\mathbf{m g} \cdot \mathbf{g}^{-1}\right)$ & $\mathbf{R}^{2}$ \\
38.698 & 2.332 & 0.936 & 0.127 & 217.39 & 0.987 \\
\hline
\end{tabular}

For the purpose of comparing the adsorption capacities of the prepared PA6/CS/GO composite nanofibers with the other adsorbent materials, the maximum adsorption capacity values were compared. Table (6) presented the comparative adsorption investigation of PA6/CS/GO adsorbent for removal of $\mathrm{Pb}^{2+}$ ions with that reported in the literature. It is clear that $\mathrm{PA6} / \mathrm{CS} / \mathrm{GO}$ has an excellent adsorption performance when compared with some other adsorbents. 
Table 6

Comparison of $\mathrm{Pb} 2+$ adsorption capacity for differently adsorbent materials.

\begin{tabular}{|c|c|c|c|}
\hline Adsorbent & $\begin{array}{l}\text { Kinds of } \\
\text { adsorbents }\end{array}$ & $\begin{array}{l}\text { Adsorption } \\
\text { capacity } \\
\left(\mathrm{mg}^{-1} \mathrm{~g}^{-1}\right)\end{array}$ & Ref. \\
\hline PA6/CS/GO & $\begin{array}{l}\text { composite } \\
\text { nanofibers }\end{array}$ & 217.39 & Present work \\
\hline Chitosan & beads & 34.98 & \multirow{3}{*}{$\begin{array}{l}\text { (Ngah and Fatinathan } \\
2010)\end{array}$} \\
\hline Chitosan-Glutaraldehyde & & 14.24 & \\
\hline Chitosan-Alginate & & 60.27 & \\
\hline $\begin{array}{l}\mathrm{Pb}^{2+} \text { ion-imprinting electrospun } \\
\text { cross- linked chitosan }\end{array}$ & nanofiber mats & 110.2 & (Li, Zhang et al. 2016) \\
\hline $\mathrm{Fe}_{3} \mathrm{O}_{4}$ /o-MWCNTs/ polyamide- 6 & $\begin{array}{l}\text { hybrid } \\
\text { nanofibrous } \\
\text { membrane }\end{array}$ & 49.3 & $\begin{array}{l}\text { (Bassyouni, } \\
\text { Mohamed et al. 2019) }\end{array}$ \\
\hline $\begin{array}{l}\text { DTPA-modified } \\
\text { chitosan/polyethylene oxide }\end{array}$ & nanofibers & 142 & $\begin{array}{l}\text { (Surgutskaia, Di } \\
\text { Martino et al. 2020) }\end{array}$ \\
\hline
\end{tabular}

\section{Conclusion}

In conclusion, the electrospun PA6/CS/GO composite nanofiber with different weight proportion of GO were fabricated successfully via electrospinning technique. The effects of various weight percentage of CS on spinnability and morphology were investigated. The SEM results of PA6/CS composite showed that the formation of uniform and bead-free nanofibers accrued. The SEM results of PA6/CS/GO composite nanofibers revealed that presence of the $\mathrm{GO}$ in the polymer matrix causes formation of the spider-web-like structure nanofibers with smaller diameter. The TGA results had proved the presence of $\mathrm{GO}$ in the scaffolds was found to have good improvement in the thermal resistance of composite nanofibers. The Young's modulus and tensile strength of PA6/CS/GO composite nanofibers were found to increase, showing a maximum Young's modulus of $9.66 \mathrm{MPa}$ and the tensile strength of $1.27 \mathrm{MPa}$ for PA6/CS/GO - 0.5 composite nanofibers. This finding confirmed the significant potential of electrospun PA6/CS/GO fibers for use as powerful nanocomposite in numerous engineering fields particularly in membrane and filtration. Finally, the adsorption study showed that the PA6/CS/GO composite nanofibers had higher potential for $\mathrm{Pb}^{2+}$ ions sorption. The investigation of kinetic and isotherm models indicated that the adsorption of $\mathrm{Pb}^{2+}$ ions using nanofibers adsorbents were best described by pseudo-first-order kinetic and Langmuir isotherm models. The maximum monolayer adsorption capacities of PA6/CS/GO composite nanofibers for $\mathrm{Pb}^{2+}$ sorption was found to be $217.39 \mathrm{mg} . \mathrm{g}-1$.

\section{Declarations}


The authors thank the University of Mazandaran, Iran for financial and other supports.

\section{Author statement}

Atefeh Moosavi: Investigation, Visualization, Writing- Original draft preparation

Seyed Reza Nabavi: Supervision, Data curation, Writing- Reviewing and Editing

\section{References}

1. Abu-Danso E et al (2018) "Synthesis of S-ligand tethered cellulose nanofibers for efficient removal of $\mathrm{Pb}$ (II) and Cd (II) ions from synthetic and industrial wastewater." 242: 1988-1997

2. Amiryaghoubi $\mathrm{N}$ et al (2021) "Recent advances in polymeric scaffolds containing carbon nanotube and graphene oxide for cartilage and bone regeneration." Materials Today Communications: 102097

3. Ardeshirzadeh B et al (2015) "Controlled release of doxorubicin from electrospun PEO/chitosan/graphene oxide nanocomposite nanofibrous scaffolds." 48: 384-390

4. Bandehali S et al (2021) "Biodegradable polymers for membrane separation." 118731

5. Banitaba SN et al (2020) Electrospun core-shell nanofibers based on polyethylene oxide reinforced by multiwalled carbon nanotube and silicon dioxide nanofillers: A novel and effective solvent-free electrolyte for lithium ion batteries. Int J Energy Res 44(8):7000-7014

6. Barzegar F et al (2015) "Preparation and characterization of poly (vinyl alcohol)/graphene nanofibers synthesized by electrospinning." 77: 139-145

7. Bassyouni D et al (2019) Fabrication and characterization of electrospun Fe304/oMWCNTs/polyamide 6 hybrid nanofibrous membrane composite as an efficient and recoverable adsorbent for removal of $\mathrm{Pb}$ (II). Microchem J 149:103998

8. Che Othman FE et al (2020) "Electrospun composites made of reduced graphene oxide and polyacrylonitrile-based activated carbon nanofibers (rGO/ACNF) for enhanced $\mathrm{CO} 2$ adsorption. " Polymers 12(9):2117

9. Cho D et al (2012) "Characterizing zeta potential of functional nanofibers in a microfluidic device." 372(1): 252-260

10. Doagou-Rad S et al (2018) Interaction of nanofillers in injection-molded graphene/carbon nanotube reinforced PA66 hybrid nanocomposites. J Polym Eng 38(10):971-981

11. Essalhi $\mathrm{M}$ et al (2013) "Response surface modeling and optimization of electrospun nanofiber membranes." 7(1)

12. Feng Z-Q et al (2020) "Porous polyacrylonitrile/graphene oxide nanofibers designed for high efficient adsorption of chromium ions (VI) in aqueous solution". Chem Eng J 392:123730

13. Geng X et al (2005) "Electrospinning of chitosan dissolved in concentrated acetic acid solution" 26(27):5427-5432 
14. Ghadamnan E et al (2019) Nano LTA zeolite in water softening process: synthesis, characterization, kinetic studies and process optimization by response surface methodology (RSM). Journal of Water Environmental Nanotechnology 4(2):119-138

15. Ghasemi S et al (2017) "Electrophoretic deposition of graphene nanosheets: A suitable method for fabrication of silver-graphene counter electrode for dye-sensitized solar cell." 520: 477-487

16. Ghorbani F, Zamanian AJe-P (2018) "Oxygen-plasma treatment-induced surface engineering of biomimetic polyurethane nanofibrous scaffolds for gelatin-heparin immobilization." 18(3): 275-285

17. He Y et al (2004) "Hydrogen bonds in polymer blends" 29(10):1021-1051

18. Heikkilä P, Harlin AJEPJ (2008) "Parameter study of electrospinning of polyamide-6" 44(10):30673079

19. Homayoni $\mathrm{H}$ et al (2009) "Electrospinning of chitosan nanofibers: Processing optimization" 77(3):656-661

20. Hummers WS Jr (1958) and R. E. J. J. o. t. a. c. s. Offeman. "Preparation of graphitic oxide" 80(6):1339-1339

21. Illing T et al (2015) "Influence of hygrothermal aging on dimensional stability of thin injection-molded short glass fiber reinforced PA6 materials." 132(28)

22. Islam MS et al (2019) "A review on fabrication of nanofibers via electrospinning their applications" 1(10):1-16

23. Jalalian N, Nabavi SR (2020) Electrosprayed chitosan nanoparticles decorated on polyamide6 electrospun nanofibers as membrane for acid fuchsin dye filtration from water. Surfaces Interfaces 21:100779

24. Jawad AH et al (2018) "Utilization of watermelon (Citrullus lanatus) rinds as a natural low-cost biosorbent for adsorption of methylene blue: kinetic, equilibrium and thermodynamic studies." 12(4): $371-381$

25. Jin L et al (2014) Fabrication, mechanical properties, and biocompatibility of reduced graphene oxide-reinforced nanofiber mats. RSC Adv 4(66):35035-35041

26. Kardas I et al (2012) "Chitin and chitosan as functional biopolymers for industrial applications." 329-373

27. Karsli NG, Aytac A (2013) Tensile and thermomechanical properties of short carbon fiber reinforced polyamide 6 composites. Composites Part B: Engineering 51:270-275

28. Karthik R, Meenakshi SJCEJ (2015) "Removal of Pb (II) and Cd (II) ions from aqueous solution using polyaniline grafted chitosan." 263: 168-177

29. Keirouz A et al (2020) "Nylon-6/chitosan core/shell antimicrobial nanofibers for the prevention of mesh-associated surgical. site infection" 18(1):1-17

30. Kennedy TW, Hudson WR (1968) "Application of the indirect tensile test to stabilized materials." Highway Research Record(235) 
31. Koosha M, Mirzadeh H (2015) Electrospinning, mechanical properties, and cell behavior study of chitosan/PVA nanofibers. Journal of Biomedical Materials Research Part A 103(9):3081-3093

32. Kummer $\mathrm{G}$ et al (2018) Development of nanofibers composed of chitosan/nylon 6 and tannin/nylon 6 for effective adsorption of $\mathrm{Cr}(\mathrm{VI})$. J Polym Environ 26(10):4073-4084

33. Leidy R et al (2019) "Use of electrospinning technique to produce nanofibres for food industries: A perspective from regulations to characterisations." 85: 92-106

34. Li J et al (2013) "Graphene oxide-reinforced biodegradable genipin-cross-linked chitosan fluorescent biocomposite film and its cytocompatibility." 8: 3415

35. Li Y et al (2016) Crosslinked chitosan nanofiber mats fabricated by one-step electrospinning and ionimprinting methods for metal ions adsorption. Science China Chemistry 59(1):95-105

36. Li Z et al (2019) Interpretation of the adsorption mechanism of Reactive Black 5 and Ponceau 4R dyes on chitosan/polyamide nanofibers via advanced statistical physics model. J Mol Liq 285:165170

37. Liu L et al (2012) "Preparation and characterization of chitosan/graphene oxide composites for the adsorption of $\mathrm{Au}$ (III) and Pd (II)." 93: 350-357

38. Liu Y et al (2014) "Facile preparation and characterization of poly (vinyl alcohol)/chitosan/graphene oxide biocomposite nanofibers." 20(6): 4415-4420

39. Liu Y et al (2014) Preparation and characterization of chitosan-based nanofibers by ecofriendly electrospinning. Mater Lett 132:23-26

40. López-Covarrubias JG et al (2019) "Electrospun nanofibers applied to dye solar sensitive cells: a review." 12(19): 3190

41. Maryšková $M$ et al (2016) "Polyamide 6/chitosan nanofibers as support for the immobilization of Trametes versicolor laccase for the elimination of endocrine disrupting chemicals." 89: 31-38

42. Moradi G, Zinadini S (2020) "A high flux graphene oxide nanoparticles embedded in PAN nanofiber microfiltration membrane for water treatment applications with improved anti-fouling performance". Iran Polym J 29(9):827-840

43. Najafabadi $\mathrm{HH}$ et al (2015) "Removal of $\mathrm{Cu} 2+, \mathrm{Pb} 2+$ and $\mathrm{Cr} 6+$ from aqueous solutions using a chitosan/graphene oxide composite nanofibrous adsorbent". Rsc Advances 5(21):16532-16539

44. Navaneethan B et al (2021) "Novel Self-Directing Single-Polymer Jet Developing Layered-Like 3D Buckled Microfibrous Scaffolds for. Tissue Engineering Applications" 13(8):9691-9701

45. Navarro-Pardo F et al (2016) "Carbon nanotube and graphene based polyamide electrospun nanocomposites: a review." 2016

46. Ngah WW, Fatinathan $\mathrm{S}$ (2010) Pb (II) biosorption using chitosan and chitosan derivatives beads: Equilibrium, ion exchange and mechanism studies. J Environ Sci 22(3):338-346

47. Nirmala R et al (2014) "Recent progress on the fabrication of ultrafine polyamide- 6 based nanofibers via electrospinning: a. topical review" 6(2):89-107 
48. Nirwan VP et al (2019) "Fabrication of stable nanofiber matrices for tissue engineering via electrospinning of bare laser-synthesized Au nanoparticles in solutions of high molecular weight chitosan." 9(8): 1058

49. Pant HR et al (2012) "Bimodal fiber diameter distributed graphene oxide/nylon-6 composite nanofibrous mats via electrospinning." 407: 121-125

50. Parlayıcı Ş et al (2019) Electrospinning of polymeric nanofiber (nylon 6, 6/graphene oxide) for removal of $\mathrm{Cr}(\mathrm{VI})$ : synthesis and adsorption studies. Journal of Analytical Science Technology 10(1):1-13

51. Paz RAd et al (2016) "Mechanical and thermomechanical properties of polyamide 6/Brazilian organoclay nanocomposites." 26(1): 52-60

52. Pervez M, J. GK, Stylios N (2018) "Investigating the synthesis and characterization of a novel "green" H2O2-assisted, water-soluble chitosan/polyvinyl alcohol nanofiber for environmental end uses." 8(6): 395

53. Qin X et al (2016) "A green technology for the synthesis of cellulose succinate for efficient adsorption of $\mathrm{Cd}$ (II) and $\mathrm{Pb}$ (II). ions" 6(32):26817-26825

54. Razzaz A et al (2016) "Chitosan nanofibers functionalized by TiO2 nanoparticles for the removal of heavy metal ions." 58: 333-343

55. Sencadas V et al (2012) "Determination of the parameters affecting electrospun chitosan fiber. size distribution morphology" 87(2):1295-1301

56. Shaker MAJ J. o. t. T. I. o. C. E (2015) "Adsorption of Co (II), Ni (II) and Cu (II) ions onto chitosanmodified poly (methacrylate) nanoparticles: dynamics, equilibrium and thermodynamics studies." 57 : 111-122

57. Shakiba M et al (2021) Development of a superhydrophilic nanofiber membrane for oil/water emulsion separation via modification of polyacrylonitrile/polyaniline composite. Polym Adv Technol 32(3):1301-1316

58. Sherlala A et al (2018) "A review of the applications of organo-functionalized magnetic graphene oxide nanocomposites for heavy metal adsorption." 193: 1004-1017

59. Silvestri $D$ et al (2019) Production of electrospun nanofibers based on graphene oxide/gum Arabic. Int J Biol Macromol 124:396-402

60. Sirviö JA and M. J. J. o. h. m. Visanko (2020) "Lignin-rich sulfated wood nanofibers as highperforming adsorbents for the removal of lead and copper from water." 383: 121174

61. Smirnova $\mathrm{N}$ et al (2019) "Optimization of mechanical properties and bioactivity of composite matrices based on chitosan and chitin nanofibril for tissue engineering." 13(5): 382-387

62. Surgutskaia NS et al (2020) Efficient $\mathrm{Cu} 2+, \mathrm{Pb} 2+$ and $\mathrm{Ni2}+$ ion removal from wastewater using electrospun DTPA-modified chitosan/polyethylene oxide nanofibers. Sep Purif Technol 247:116914

63. Tamayo Marín JA et al (2019) "Biocompatible and antimicrobial electrospun membranes based on nanocomposites of chitosan/poly (vinyl alcohol)/graphene oxide." 20(12): 2987 
64. Tavakoli $\mathrm{M}$ et al (2020) "Evaluation of physical, mechanical, and biodegradation of chitosan/graphene oxide composite. as bone substitutes" 59(4):430-440

65. Thenmozhi S et al (2017) "Electrospun nanofibers: New generation materials for advanced applications." 217: 36-48

66. Thompson C et al (2007) "Effects of parameters on nanofiber diameter determined from electrospinning model." 48(23): 6913-6922

67. Tsou S-Y et al (2013) Rheological aspect on electrospinning of polyamide 6 solutions. European polymer journal 49(11):3619-3629

68. Wang $X$ et al (2013) "Electro-spinning/netting: A strategy for the fabrication of three-dimensional polymer nano-fiber/nets." 58(8): 1173-1243

69. Xue $J$ et al (2019) "Electrospinning and electrospun nanofibers: Methods. materials applications" 119(8):5298-5415

70. Yang S et al (2018) "Thermal and mechanical performance of electrospun chitosan/poly (vinyl alcohol) nanofibers with graphene oxide." 1(4): 722-730

71. Yildirim-Aksoy M and B. J. J. o. a. m. Beck (2017) "Antimicrobial activity of chitosan and a chitosan oligomer against bacterial pathogens of warmwater fish." 122(6): 1570-1578

72. Yin X et al (2020) "Ultra-fine electrospun nanofibrous membranes for multicomponent wastewater treatment. Filtration adsorption" 242:116794

73. Young RJ et al (2012) "The mechanics of graphene nanocomposites: a review" 72(12):1459-1476

74. Zhang $\mathrm{H}$ et al (2009) "Studies on electrospun nylon-6/chitosan complex nanofiber interactions." 54(24): 5739-5745

75. Zhang L et al (2016) "Removal of heavy metal ions using chitosan and modified chitosan. A review" 214:175-191

76. Zhang $S$ et al (2017) "A controlled design of ripple-like polyamide-6 nanofiber/nets membrane for high-efficiency. air filter" 13(10):1603151

77. Zhang $S$ et al (2019) "Lead and cadmium adsorption by electrospun PVA/PAA nanofibers: Batch, spectroscopic, and modeling study." 233: 405-413

78. Zhang $Y$ et al (2008) "Chitosan nanofibers from an easily electrospinnable UHMWPEO-doped chitosan solution system." 9(1): 136-141

79. Zhao X et al (2018) "Biomimetic mineralization of carboxymethyl chitosan nanofibers with improved osteogenic activity in vitro and in vivo." 195: 225-234

\section{Figures}

\section{Figure 1}


Steps of preparing the composite polymer solutions, electrospinning process, and adsorption study schematically.
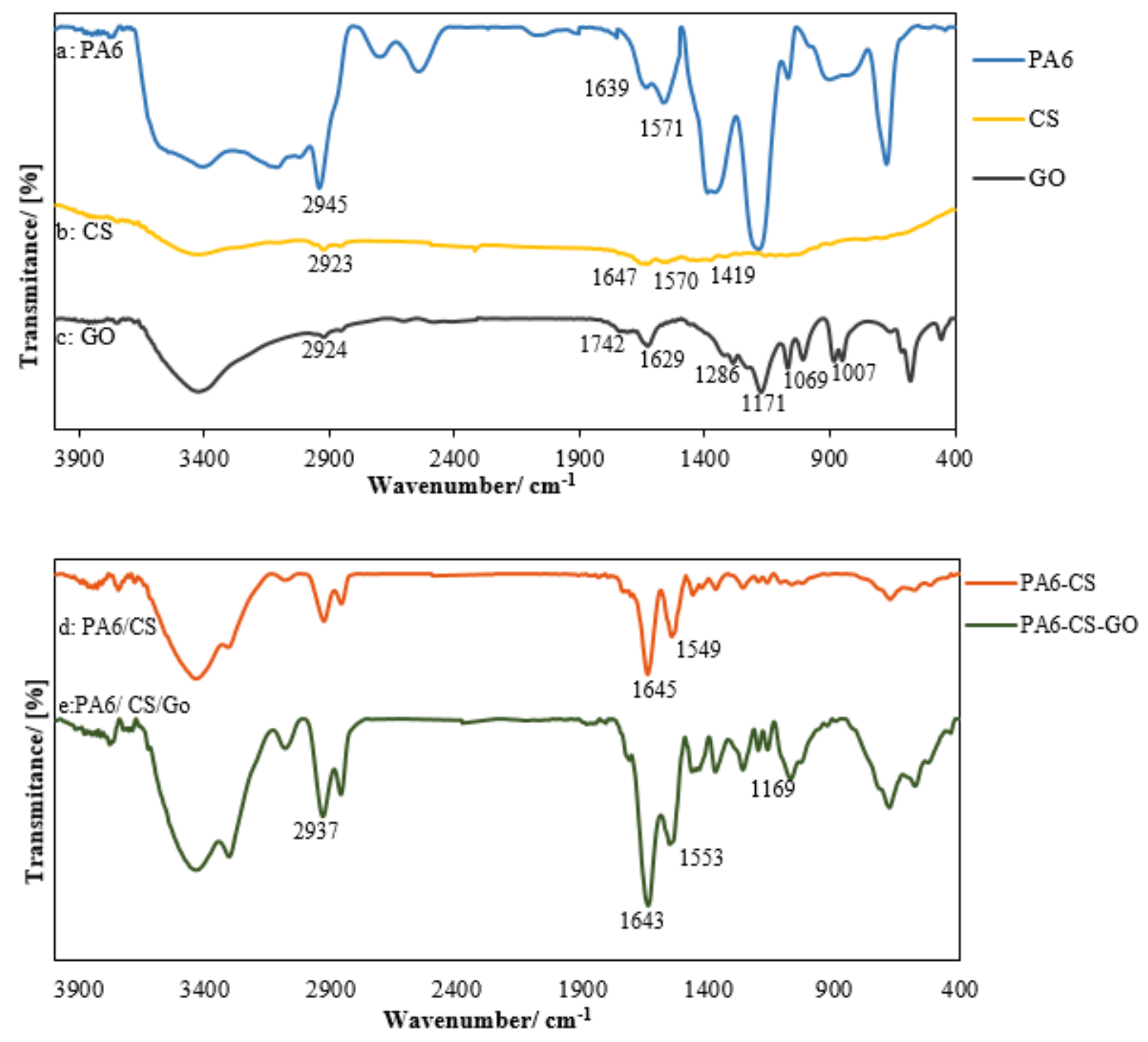

Figure 2

The FT-IR spectrum of nanofibers of a) PA6, b)CS, c) GO and Composite nanofibers of d) PA6/CS e) and e) PA6/CS/GO 

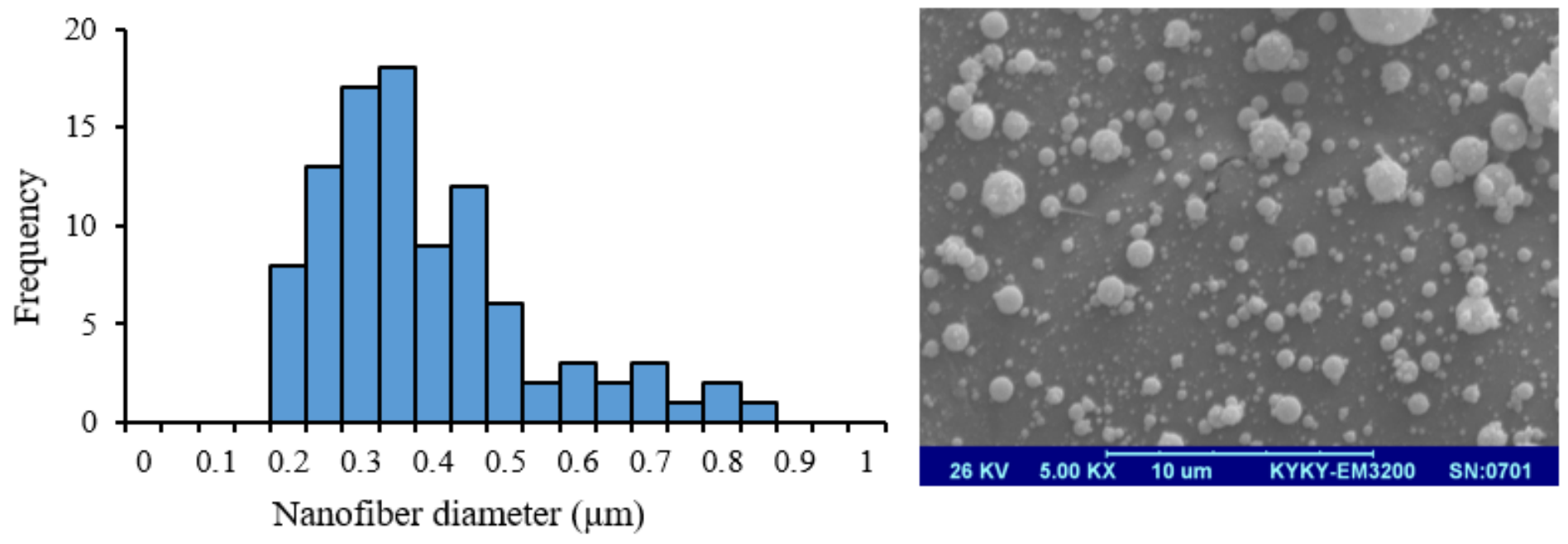

Figure 3

The SEM images of $7 \mathrm{wt} \% \mathrm{CS}$ solution in acetic acid by electrospinning conditions of applied voltage 25 $\mathrm{kV}$, injection rate of $0.6 \mathrm{~mL} . \mathrm{h}^{-1}$, and syringe tip distance to collector $160 \mathrm{~mm}$.

Figure 4

The SEM images and the histogram diagrams of electrospinning nanofibers of PA6/ CS with CS weight percentages of; a) $0 \%$, b) $2 \%$, c) $4 \%$, d) $8 \%$, e) $12 \%$, f) $16 \%$, g) $20 \%$, and h) $24 \%$. 

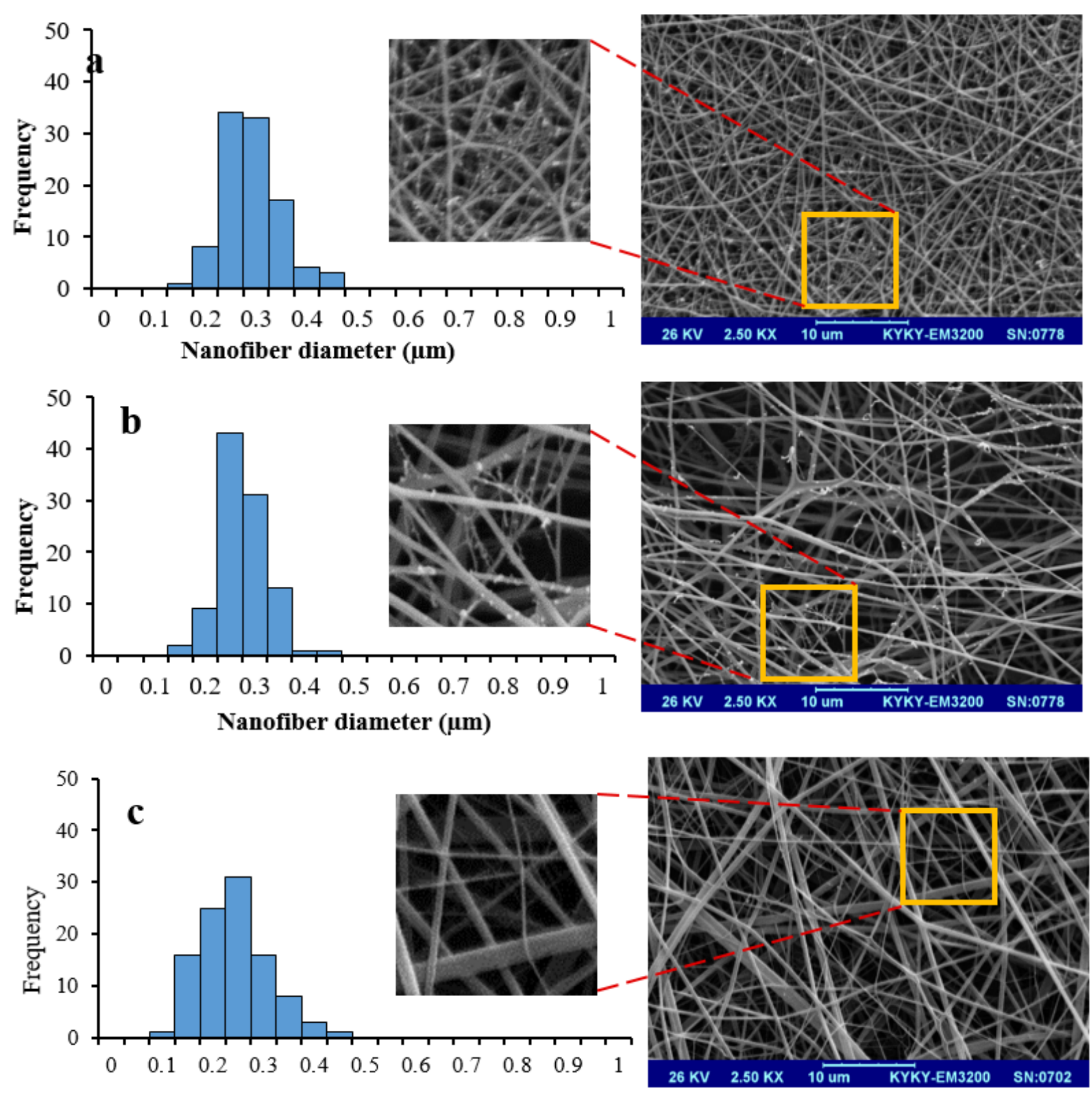

Nanofiber diameter $(\mu \mathrm{m})$

Figure 5

The SEM image of PA6/CS/GO composite nanofibers with $\mathrm{GO}$ by weight percentages a) $0.1 \% \mathrm{~b}$ ) $0.25 \% \mathrm{c}$ ) $0.5 \%$ in the system of a formic acid solvent by electrospinning conditions of applied voltage $25 \mathrm{kV}$, injection rate of $0.6 \mathrm{~mL} . \mathrm{h}^{-1}$, and syringe tip distance to collector $160 \mathrm{~mm}$. 

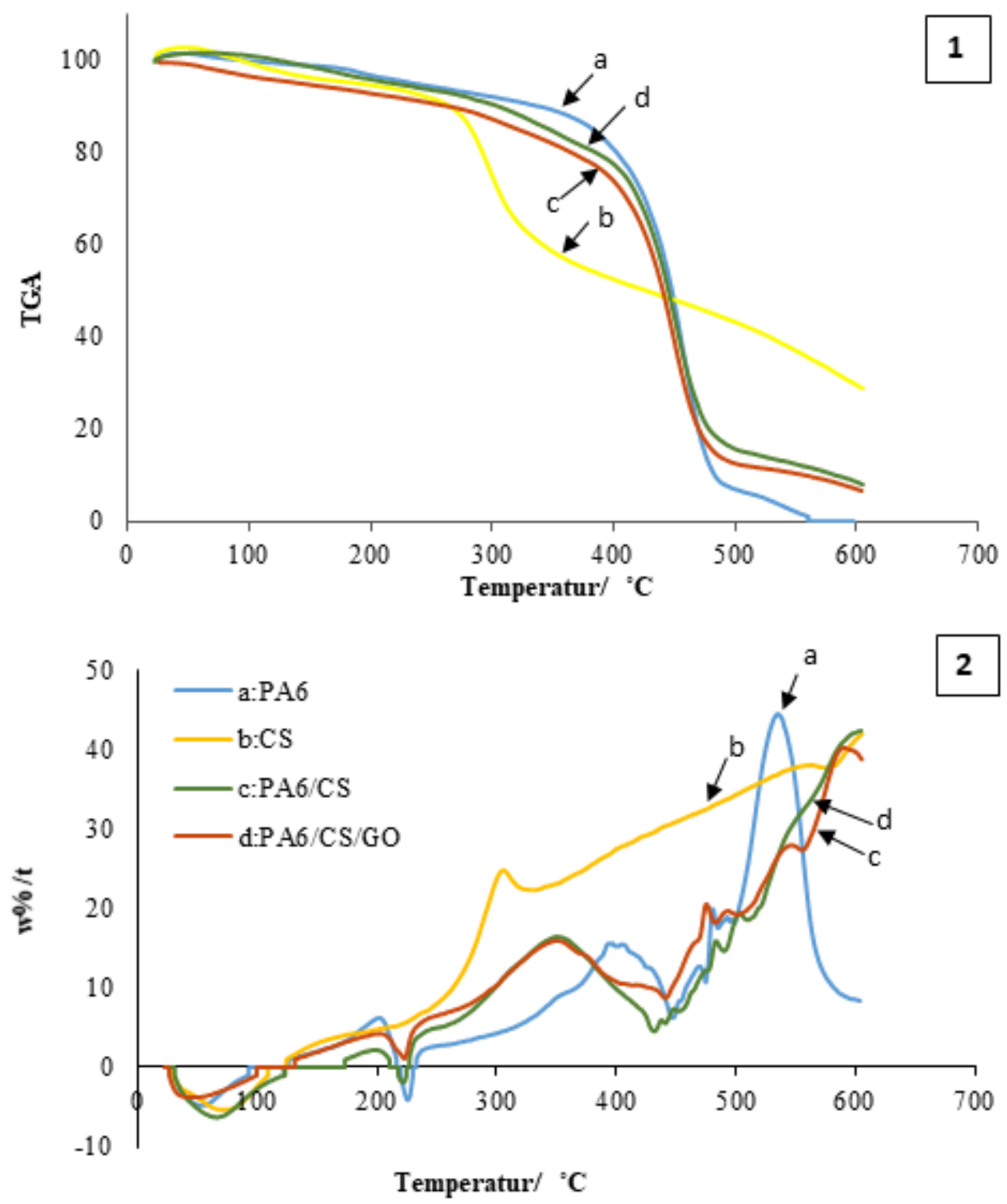

Figure 6

The graphs of TGA and DTG correspond to a) PA6 electrospun nanofibers, b) CS, c) the electrospun composite nanofibers of PA6/CS $16 \%$, and d) $0.25 \%$ PA6/CS-GO. 


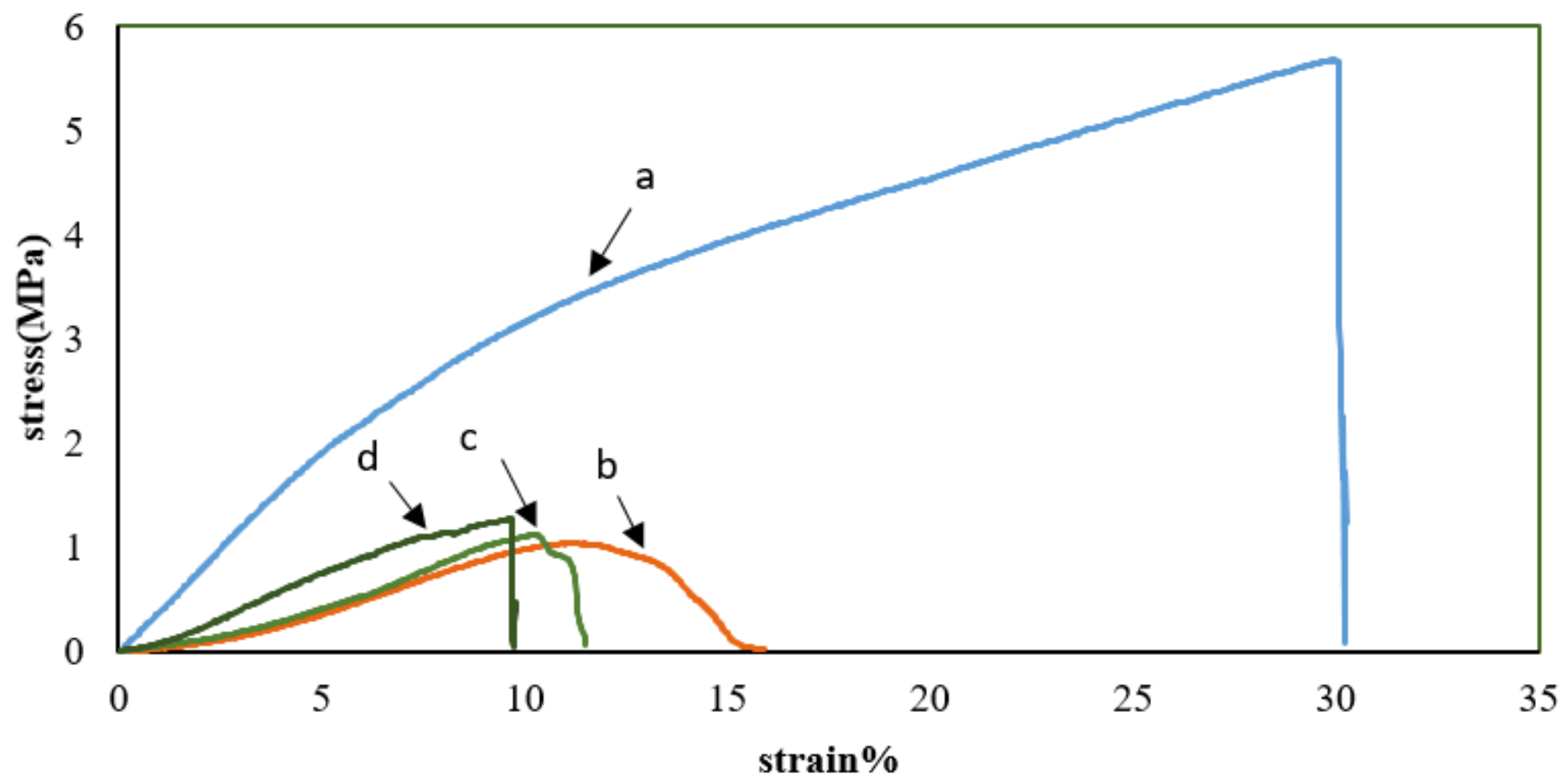

$-\mathrm{a}: \mathrm{PA} 6-\mathrm{b}: \mathrm{PA} 6 / \mathrm{CS} 16 \%-\mathrm{c} \% \mathrm{PA} 6 / \mathrm{CS} / \mathrm{GO} 0.25 \%-\mathrm{d}: \mathrm{PA} 6 / \mathrm{CS} / \mathrm{GO} 0.5 \%$

Figure 7

The stress-strain graph of a) PA6 electrospun nanofibers, and the electrospun composite nanofibers of b) PA6/CS $16 \%$, c) PA6/CS/GO 0.25\%, and d) PA6/CS/GO 0.5\%. 


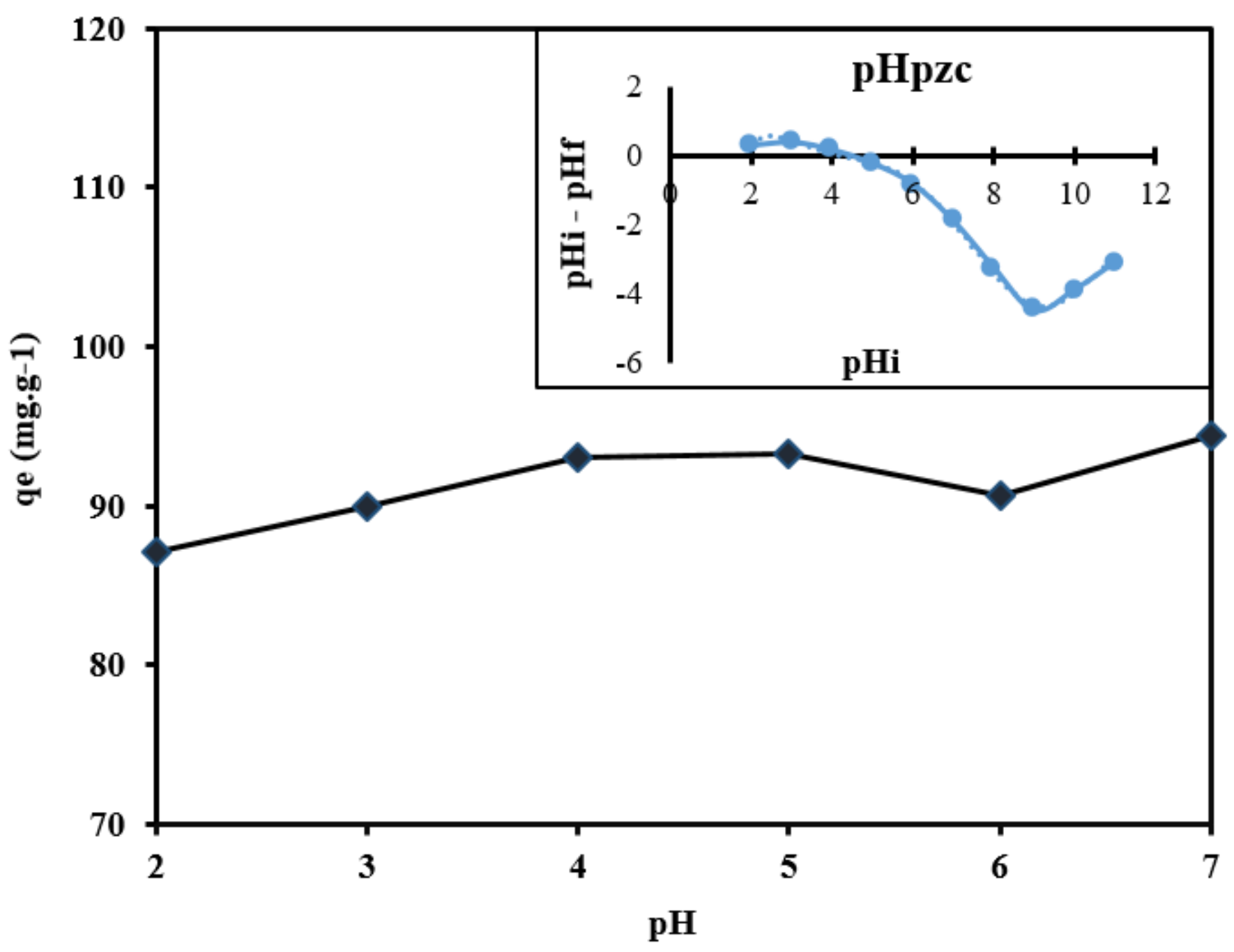

Figure 8

Effect of $\mathrm{pH}$ on the adsorption of $\mathrm{Pb}^{2+}$ ions using $\mathrm{PA6} / \mathrm{CS} / \mathrm{GO}$ composite nanofibers.

Figure 9

Effect of adsorbent dosage on the adsorption of $\mathrm{Pb}^{2+}$ ions using PA6/CS/GO composite nanofibers a) ,b)

Figure 10

The adsorption kinetics graph of $\mathrm{Pb}^{2+}$ ions adsorption using PA6/CS/GO composite nanofibers. 